\title{
COVID-19 hotspots through clusters analysis in France (may-October 2020): where should we track the virus to mitigate the spread?
}

Guillaume Spaccaferri 미, Clémentine Calba, Pascal Vilain, Loïc Garras, Cécile Durand, Corinne Pilorget, Nahida Atiki, Pascale Bernillon, Laëtitia Bosc, Erica Fougère, Jean-Baptiste Hanon, Valérie Henry, Caroline Huchet-Kervella, Mélanie Martel, Valérie Pontiès, Damien Mouly, Enguerrand Rolland du Roscoat, Stéphane Le Vu, Jean-Claude Desenclos, Anne Laporte, Regional MONIC group and Patrick Rolland

\begin{abstract}
Background: In France, the lifting of the lockdown implemented to control the COVID-19 first wave in 2020 was followed by a reinforced contact-tracing (CT) strategy for the early detection of cases and transmission chains. We developed a reporting system of clusters defined as at least three COVID-19 cases, within seven days and belonging to the same community or having participated in the same gathering, whether they know each other or not. The aim of this study was to describe the typology and criticality of clusters reported between the two lockdowns in France to guide future action prioritisation.

Methods: In this study we describe the typology and criticality of COVID-19 clusters between the two lockdowns implemented in France (between May and end of October 2020). Clusters were registered in a national database named "MONIC" (MONItoring des Clusters), established in May 2020. This surveillance system identified the most affected communities in a timely manner. A level of criticality was defined for each cluster to take into consideration the risk of spreading within and outside the community of occurrence, and the health impact within the community. We compared the level of criticality according to the type of community in which the cluster occurred using Pearson's chi-square tests.
\end{abstract}

\footnotetext{
* Correspondence: guillaume.spaccaferri@santepubliquefrance.fr

Guillaume Spaccaferri and Clémentine Calba contributed equally as first authors.

Santé publique France, 12 Rue du Val d'Osne, 94410 Saint-Maurice, France
}

(c) The Author(s). 2021 Open Access This article is licensed under a Creative Commons Attribution 4.0 International License, which permits use, sharing, adaptation, distribution and reproduction in any medium or format, as long as you give appropriate credit to the original author(s) and the source, provide a link to the Creative Commons licence, and indicate if changes were made. The images or other third party material in this article are included in the article's Creative Commons licence, unless indicated otherwise in a credit line to the material. If material is not included in the article's Creative Commons licence and your intended use is not permitted by statutory regulation or exceeds the permitted use, you will need to obtain permission directly from the copyright holder. To view a copy of this licence, visit http://creativecommons.org/licenses/by/4.0/. The Creative Commons Public Domain Dedication waiver (http://creativecommons.org/publicdomain/zero/1.0/) applies to the data made available in this article, unless otherwise stated in a credit line to the data. 
Results: A total of 7236 clusters were reported over the study period, particularly in occupational environment $(25.1 \%, n=1813)$, elderly care structures $(21.9 \%, n=1586)$, and educational establishments $(15.9 \%, n=1154)$. We show a shift over time of the most affected communities in terms of number of clusters. Clusters reported in occupational environment and the personal sphere had increased during summer while clusters reported in educational environment increased after the start of the school year. This trend mirrors change of transmission pattern overtime according to social contacts. Among all reported clusters, $43.1 \%$ had a high level of criticality with significant differences between communities $(p<0.0001)$. A majority of clusters had a high level of criticality in elderly care structures (82.2\%), in disability care centres (56.6\%), and health care facilities (51.7\%).

Conclusion: These results highlight the importance of targeting public health action based on timely sustained investigations, testing capacity and targeted awareness campaigns. The emergence of new SARS-CoV-2 variants strengthen these public health recommendations and the need for rapid and prioritise vaccination campaigns.

Keywords: COVID-19, Hotspots, Clusters, Descriptive analysis, Criticality, Public health

\section{Background}

The coronavirus disease 2019 (COVID-19) is caused by severe acute respiratory syndrome corona virus 2 (SARS-CoV-2). The virus was first detected in Wuhan province, China, in December 2019. Since then, the epidemic has progressed rapidly into a pandemic. The disease can result in severe and even fatal respiratory diseases such as acute respiratory distress syndrome [1]. Thus, the pandemic led to an exponential growth in hospital admissions highlighting a risk of saturation of local intensive care units [2].

In France, the first wave of COVID-19 epidemic was controlled by a lockdown from March 17 to May 10, 2020, bringing all regions below the daily hospital admissions threshold of 1 per 100,000 inhabitants [2-4]. The lifting of the lockdown was followed by a resumption of activities and a reinforced contact-tracing (CT) strategy. This strategy aimed at the early detection of cases and transmission chains, including the follow-up of clusters. After a steady rise of the cases starting from August 2020 , a second wave was observed leading to a second lockdown from October 30 to December 14 [5]. The second lockdown was lifted on December 15 and a national curfew was implemented.

The repetition of epidemic waves highlights the need for anticipating COVID-19 future hotspots in order to mitigate the spread and to limit the disease burden. The aim of the current study was to describe the typology and criticality of clusters reported between the first two lockdowns in France and their change over time to guide future action prioritisation.

\section{Methods}

We defined a COVID-19 case as a person, symptomatic or not, with a positive SARS-CoV-2 RT-PCR on a nasopharyngeal swab. A cluster was defined as the identification of at least three COVID-19 cases, within seven days and belonging to the same community or having participated in the same gathering, whether they know each other or not. Santé publique France developed a guide for COVID-19 clusters' investigation and evaluation, which is available online [6].

Clusters were detected through the CT strategy or voluntarily notified by affected communities. The CT strategy aimed at the identification of high-risk contacts (forward tracing) and did not target the origin of contamination (backward tracing). Clusters were registered at the regional level in a national database named "MONIC" (MONItoring des Clusters). All 18 French regions were involved in this surveillance, including the five overseas regions. Familial clusters (i.e. people sharing the same home) were not targeted in this surveillance because of the assumed low risk of spreading outside the family home. However, social gathering between several family branches were included. For each cluster, descriptive data were collected and regularly updated based on results of epidemiological investigations conducted by local health agencies, including: date of reporting, type and size of the exposed community, date of symptom onset (or date of sample) of the first and the latest cases, number of cases, hospitalisations and deaths.

The results of the investigations were used to define a level of criticality (low, moderate, high) for each cluster, according to qualitative and quantitative criteria (Table 1). These criteria allowed to take into consideration the risk of spreading within and outside the community of occurrence, and the health impact within the community. The risk of spreading was based on the size of the population that has been exposed (i.e. the larger the population, the higher the risk), and on difficulties to implement health management measures. This risk was used to refine the criticality level during investigations [6]. The level of criticality was regularly updated 
according to the evolution of the situation (e.g. number of reported cases). The criteria used to assess the level of criticality were included in MONIC and did not change during the study period.

MONIC included data related to the community type where the cluster was reported (e.g. educational establishment, occupational environment) and the level of criticality. These data were analysed to describe the national distribution of reported clusters within communities, in total and over time. We compared the level of criticality according to the community type in which clusters occurred using Pearson's chi-square tests (Stata V12).

\section{Results}

\section{Distribution of clusters among communities over time}

Between May and October 2020, 7236 clusters were reported, particularly in occupational environment (25.1\%, $n=1813)$, elderly care structures $(21.9 \%, n=1586)$, and educational establishments $(15.9 \%, n=1154)$ (Fig. 1).

The number of reported clusters and the distribution of affected communities changed over time. In May and June, following the lifting of the first lockdown, 468 clusters were reported. The proportion of clusters was the highest in elderly care structures $(29.9 \%, n=140)$, health care facilities $(18.2 \%, n=85)$, occupational environment $(16.5 \%, n=77)$, and vulnerable populations (migrants and travellers communities, penal institutions, social integration centres, and child social welfare structures) $(16.5 \%, \mathrm{n}=77)$. During summer holidays (July-August), the number of clusters doubled $(n=970)$, mainly due to the abrupt onset of clusters in occupational environment $(n=343)$ and personal sphere (family meetings, social gatherings, and sporting activities) $(n=341)$, representing respectively 35.4 and $35.2 \%$. Over the next period (September-October), the number of clusters increased at a faster pace $(n=5798)$ due to the emergence of outbreaks in educational establishments $(19.2 \%, n=1111)$, the resurgence of clusters in elderly care structures $(23.2 \%, n=1348)$ while contaminations in the occupational environment remained at a high level $(24.0 \%, n=$ 1393).

\section{Relationship between level of criticality and community type}

Among the 7236 reported clusters, $43.1 \%$ had a high level of criticality (from 19.6 to $82.2 \%$ according to the community type, $p<0.0001)$ and an average of 15 cases per cluster were reported (from 8 to 27) (Table 2).

A large majority of clusters (82.2\%) had a high level of criticality in elderly care structures where an average of 27 cases were reported. To a lesser extent, most of clusters had a high level of criticality in disability care centres $(56.6 \%)$ and health care facilities (51.7\%) with an average of 14 and 15 cases respectively. Above $40 \%$ of clusters in vulnerable populations had a high level of criticality, particularly for migrants and travellers' communities, penal institutions, social integration centres fostering people living in precarious situation, and homeless people. An average of 10 cases were reported in these communities, from 7 in child social welfare structures to 12 in migrants and travellers' communities.

In educational establishments, the proportion of clusters at high criticality was much lower $(26.4 \%$ with high criticality) but differed by educational level $(p<0.0001)$ : it was less than $20 \%$ in secondary and lower level schools, whereas it was $>40 \%$ for post-secondary level which includes older people with greater social interaction. Disparities were also found in the average number of cases reported, from $<10$ in secondary and lower level schools to 34 in post-secondary level.

Criticality of COVID-19 clusters varied by type of occupational environment $(p<0.0001)$ : it was high for nearly $50 \%$ of clusters reported in food industries (46.8\%) compared to $\leq 25 \%$ for the other sectors. Indeed, an average number of 20 cases were reported in food industries whereas it was $<10$ in the other sectors. Although the total number of clusters reported in the public administration sector (e.g. various public services, local authorities, police, firefighters ...) was large $(n=$ 497), the level of criticality was mostly low to moderate with an average number of 8 cases per cluster. A large number of clusters $(n=875)$ was reported within the personal sphere but less than $30 \%$ of these had a high level of criticality, with an average number of 9 cases.

\section{Discussion}

The number of clusters reported in France increased dramatically over time, in accordance with the epidemic dynamic, and the type of communities that were the most affected shifted over time. Elderly care structures, health care facilities, and vulnerable populations were among the most affected communities at the end of the first lockdown (May-June). These structures were also the most targeted by testing effort. The number of clusters increased thereafter (July-August) with the resumption of activities and social interactions, and the relaxation in the application of barrier measures [7]. The occupational environment and personal sphere may have thus facilitated the spread of the virus during this time [8]. The number of clusters amplified substantially in September, in conjunction with the end of summer holidays, the re-opening of schools and insufficiently protected (i.e. non-mandatory wearing of surgical mask), increased social interactions.

Clusters criticality was particularly elevated for communities with high prevalence of medical risk-factors but also for which health protection measures (physical 
Table 1 Epidemiological criteria to assess the level of criticality of the clusters

\begin{tabular}{|c|c|c|c|}
\hline Epidemiological criteria & Category A & Category B & Category C \\
\hline Number of cases & $<5$ & 5 to 9 & $>9$ \\
\hline Ratio number for cases/community size & $<5 \%$ & $10 \%$ & $15 \%$ \\
\hline Vulnerability factors & None & Medical $^{a}$ & Social ${ }^{b}$ and medical \\
\hline Severity factors & $\begin{array}{l}\text { No hospitalisation and no } \\
\text { death }\end{array}$ & $\begin{array}{l}\text { Less than } 5 \text { hospitalisations, } \\
\text { no death }\end{array}$ & $\begin{array}{l}\text { More than } 5 \text { hospitalisations and/ } \\
\text { or } \geq 1 \text { death }\end{array}$ \\
\hline $\begin{array}{l}\text { Time period between last case onset of } \\
\text { symptoms and signal }\end{array}$ & $\leq 7$ days & 8 to 14 days & 14 days \\
\hline Risk of spreading & Low & Moderate & High \\
\hline Level of criticality & \multicolumn{3}{|c|}{$\begin{array}{l}\text { Low: only category } \mathbf{A} \text { criteria } \\
\text { Moderate: at least one category B criteria without C } \\
\text { High: at least one category } \mathbf{C} \text { criteria }\end{array}$} \\
\hline
\end{tabular}

a Population with elderly people, people with comorbidities or with immunodeficiency

${ }^{b}$ Disadvantage and fragile environment, people with difficulty accessing health care, language and/or cultural barriers

distancing, wearing of masks) were difficult to implement (old age, disability, social deprivation ...) [9]. These difficulties lead to a high number of cases reported both for patients/residents and social/health care workers $(\mathrm{HCW})$. Heavy workload and understaffing faced by these workers may have also contributed to the dissemination of the virus within these communities.

High level of criticality reflects the impact within a community (i.e. severity) but also the risk of spreading to the general population. Among occupational environment, clusters that occurred in food industry plants and more specifically slaughterhouses very often had high level of criticality because of the high number of cases reported. This was mainly due to environmental factors and work conditions which favour the spread of the virus [10]. Similarly in post-secondary school where increased social interactions favoured multiple contaminations and hence the occurrence of clusters at high levels of criticality [11]. In the personal sphere, the level of criticality was lower but clusters were more numerous, particularly during summer.

Possible overlaps between clusters and communities may have occurred, especially in the personal sphere for which family meetings could also be wider social gatherings. The number of clusters in social gatherings was probably highly underestimated due to the difficulty of the CT program to identify chains of transmission among people that do not necessarily know each other, such as in bars, restaurants, fitness centres, public transports or cultural events. The number of cases reported for these clusters was probably also underestimated. Generally, the availability of COVID-19 biological tests may have had an impact on the number of cases reported in each cluster as well as the number of reported

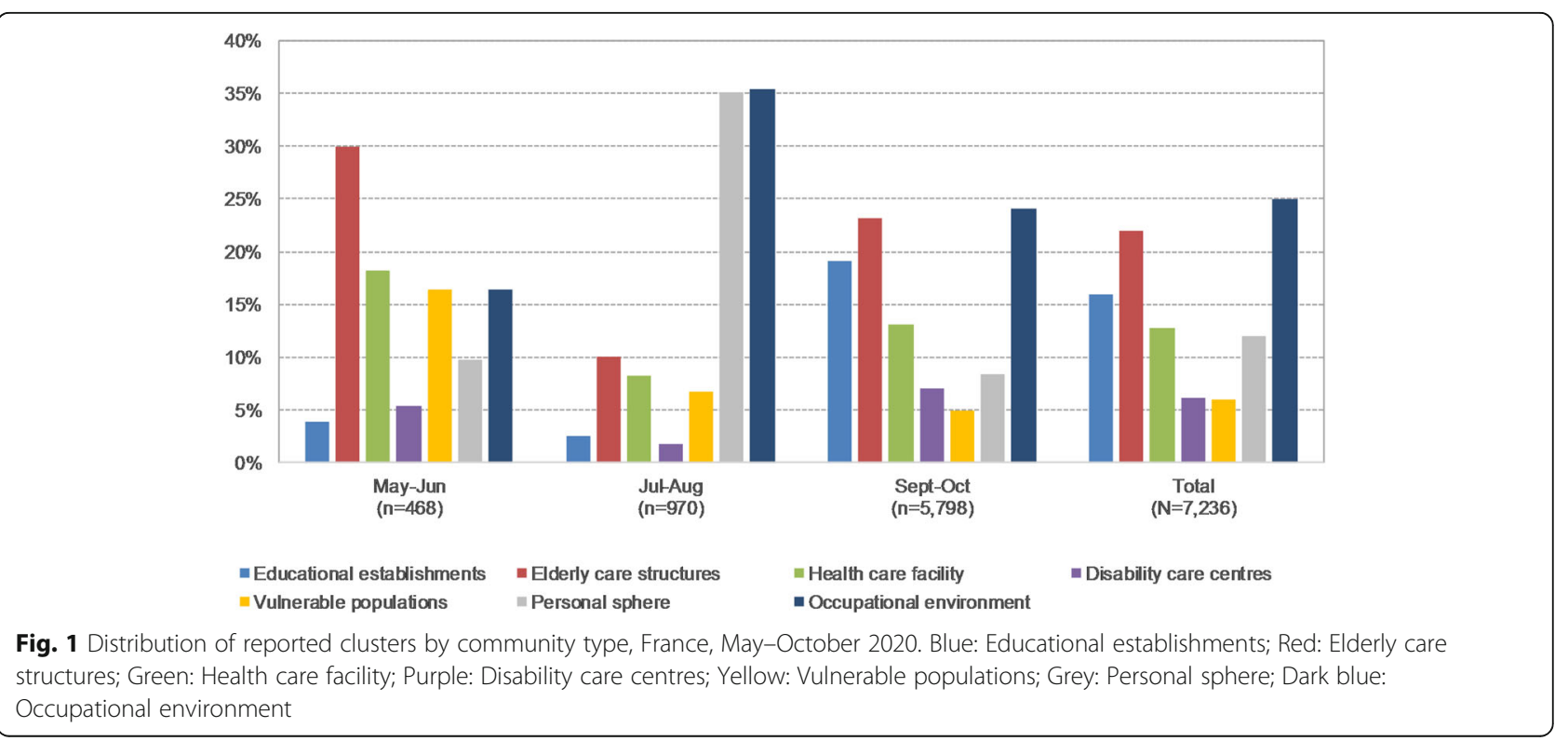


Table 2 Communities with clusters reported, ranked by level of criticality, France, May-October 2020

\begin{tabular}{|c|c|c|c|c|c|}
\hline \multirow{2}{*}{ Community } & \multirow{2}{*}{$\begin{array}{l}\text { Number } \\
\text { of clusters }\end{array}$} & \multirow{2}{*}{$\begin{array}{c}\text { Mean number } \\
\text { of cases }\end{array}$} & \multicolumn{3}{|c|}{ Level of criticality (\%) ${ }^{c}$} \\
\hline & & & Low & Moderate & High \\
\hline Elderly care structures & 1,586 & 27 & 4.8 & 13.0 & 82.2 \\
\hline Disability care centres & 449 & 14 & 13.3 & 30.1 & 56.6 \\
\hline Health care facilities & 926 & 15 & 13.8 & 34.5 & 51.7 \\
\hline Vulnerable populations & 433 & 10 & 23.8 & 32.8 & 43.4 \\
\hline Migrants and travellers communities & 97 & 12 & 15.5 & 26.8 & 57.7 \\
\hline Penal institutions & 72 & 11 & 20.8 & 30.6 & 48.6 \\
\hline Social integration centres & 184 & 11 & 25.5 & 34.3 & 40.2 \\
\hline Child social welfare structures & 80 & 7 & 32.4 & 38.8 & 28.8 \\
\hline Personal sphere & 875 & 9 & 33.4 & 40.0 & 26.6 \\
\hline Family meetings & 216 & 11 & 29.2 & 41.7 & 29.1 \\
\hline Social gatherings & 338 & 10 & 30.8 & 40.2 & 29.0 \\
\hline Sporting activities & 321 & 8 & 39.0 & 38.6 & 22.4 \\
\hline Educational establishments ${ }^{a}$ & 1,154 & 18 & 42.3 & 31.3 & 26.4 \\
\hline Post-secondary level & 414 & 34 & 27.3 & 31.2 & 41.5 \\
\hline Secondary level & 475 & 9 & 48.8 & 31.4 & 19.8 \\
\hline Primary level & 116 & 6 & 59.5 & 29.3 & 11.2 \\
\hline Pre-primary level & 54 & 5 & 59.3 & 35.2 & 5.5 \\
\hline Occupational environment ${ }^{b}$ & 1,813 & 8 & 45.7 & 34.7 & 19.6 \\
\hline Food industries & 79 & 20 & 32.9 & 20.3 & 46.8 \\
\hline Sporting and leisure activities & 76 & 8 & 38.1 & 36.9 & 25.0 \\
\hline Public administration & 500 & 8 & 39.2 & 37.2 & 23.6 \\
\hline Restauration services & 78 & 6 & 50.0 & 34.6 & 15.4 \\
\hline Wholesale & 90 & 7 & 51.1 & 36.7 & 12.2 \\
\hline Nurseries/Child care & 180 & 5 & 61.1 & 32.8 & 6.1 \\
\hline Total & 7,236 & 15 & 27.3 & 29.6 & 43.1 \\
\hline \multicolumn{6}{|l|}{${ }^{a}$ Educational level unknown for 95 clusters } \\
\hline \multicolumn{6}{|c|}{${ }^{b}$ Detailed for sectors with at least 50 clusters } \\
\hline${ }^{c} p<0.0001$ & & & $0 \%$ & $25 \%$ & $50 \%$ \\
\hline
\end{tabular}

clusters by community type, irrespective of the region. Because of a lack of testing capacity in the initial stages, testing campaigns were mainly implemented in communities where CT was limited and/or for which the criticality could be greater. At a later stage, when the testing capacity had increased, testing campaigns were implemented at a larger scale.
Although our monitoring system had several limitations (including potential lack of completeness and representativeness), it has been helpful to target and adapt control efforts at the national and territorial levels. The analysis of data collected through this system helped in providing public health recommendations to better anticipate future actions. Furthermore, information related 
to contamination circumstances would increase the understanding of cluster occurrence.

The early detection of clusters and isolation of cases are of paramount importance to mitigate the spread $[8$, 12, 13]. Moreover, regular analysis of clusters should alert on specific situations (e.g. high number of clusters or cases in specific communities) to conduct targeted awareness campaigns. During high circulation, investigations of clusters should focus on hotspots to limit the epidemic impact. Testing campaigns targeting at-risk communities and populations with poor access to health care system should limit disease burden. These communities would also benefit from adapted support, human resources and appropriate equipment to better manage outbreaks.

The emergence of new SARS-CoV-2 variants strengthen these public health recommendations. Rapid and prioritised vaccination campaigns, targeting both patients/residents and professionals in hotspots remain a key point to mitigate spread and limit the burden of the virus.

\section{Conclusion}

An increase of COVID-19 clusters was observed in France between the two lockdowns. There was a shift over time in the type of affected communities in relation to the population lifestyle dynamic. Hotspots were mostly found in communities with at-risk populations and/or where control measures were difficult to implement. Such communities should benefit from timely testing campaigns and granted of appropriate resources for rapid control including vaccination. When low virus circulation level is achieved, investigations of all clusters need to be sustained to mitigate the spread, with a special attention for most susceptible communities. Targeted prevention and control measures focusing on the most affected communities over time remain a key point to contain and flatten the COVID-19 curve. The advent of new SARS-CoV-2 variants and widespread availability of vaccines need to be taken into account to refine public health interventions aimed at controlling clusters of SARS-COV-2 intervention.

\section{Abbreviation \\ CT: contact-tracing; HCW: Health care workers}

\section{Acknowledgements}

The authors gratefully acknowledge all people in charge of contact-tracing in the Regional Health Agencies and the Regional Health Insurance Fund; and the following Santé publique France members for earlier discussions and contributions of the study: Fatima Aït Belghiti, Pierre Arwidson, Cynthia Bessarion, Isabelle Bonmarin, Sacha Camail, Christine Campèse, Stéphanie Champion, Fanny Chereau, Marie Deliberos, Gilles Delmas, Joël Deniau, Julie Figoni, Emmanuelle Hamel, Emmanuel Lahaie, Laurian Lassara, Mélina Le Barbier, Vanessa Lemoine, Etienne Lucas, Sylvie Quelet, Sandrine Randriamampianina, Sabira Smaili, Morgane Stempfelet, Anouk Tabai, Claudine Tanguy, Minh Tai Vo Van, Hélène Therre, Sophie Vaux.
The Regional MONIC group: Laetitia Ali Oicheih, Audrey Andrieu, Lyderic Aubert, Elsa Balleydier, Delphine Barataud, Lorène Belkadi, Anne Bernadou, Elise Brottet, Oriane Broustal, Luisiane Carvalho, Delphine Casamatta, Christine Castor, Olivier Catelinois, Pascal Chaud, Sonia Chene, Elise Chiron, Amandine Cochet, Sandrine Coquet, Jamel Daoudi, Camille Davisse-Paturet, Charlotte De Latour, Virginie de Lauzun, Emmanuel Delmas, Joël Deniau, Frédérique Dorléans, Cécile Durand, Aurélie Etienne, Sullivan Evain, Claire Fesquet, Caroline Fiet, Laurent Filleul, Noémie Fortin, Nelly Fournet, Florian Franke, Gaelle Gault, Philippe Germonneau, Franck Golliot, Clémence Grave, Sophie Grellet, Manon Guidarelli, Anne Guinard, Catherine Ha, Eline Hassan, Youssouf Hassani, Alice Herteau, Guillaume Heuze, Pascal Jehannin, Tatiana Junker, Lisa King, Magali Koroscowski, Annabelle Lapostole, Sophie Larrieu, Jean-Luc Lassalle, Ghislain Leduc, Anne-Hélène Liebert, Pascaline Loury, Sarah Mahdjoub-Assaad, Helene Maizi, Philippe Malfait, Quiterie Mano, Nadège Marguerite, Romain Marmorat, Charlotte Maugard, Christine Meffre, Luce Menudier, Laure Meurice, Hadidja Minihadji, Gabriela Modenesi, Marie-Anne Montaufray, Esra Morvan, Bakhao Ndiaye, Jena-Rodrigue Ndong, Ursula Noury, Eole Nyangwile, Ronan Ollivier, Fanny Parenton, Laurence Pascale, Gwénola Picard, Jérôme Pouey, Dorothée Provost, Julie Prudhomme, Sophie Raguet, Lauriane Ramalli, Olivier Retel, Adeline Riondel, Stéphanie Riviere, Maëlle Robert, Cyril Rousseau, Maoulide Saindou, Arnoo Shaiykova, Anna Siguier, Leslie Simac, Jean-Louis Solet, Ibtissame Soulaimana, Marion Subiros, Tiphanie Succo, Jeanne Tamarelle, Garance Terpant, Elodie Terrien, Sabrina Tessier, Médicoulé Traore, Morgane Trouillet, Aymeric Ung, Emmanuelle Vaissière, Caroline Vanbockstael, Nicolas Vincent, Muriel Vincent, Karine Wyndels, Jenifer Yaï.

\section{Authors' contributions}

GS, CC and PR coordinated the study, conducted the analyses and wrote the manuscript with input from all authors. PV, LG, CD, CP and the Regional MONIC group made substantial contributions to the acquisition of data and were responsible of data management. NA, PB, LB, EF, JBH, VH, CHK, MM, VP, DM, ERDR, SLV, JCD and AL helped in choosing the methods and contributed to the interpretation of the results. All authors read and approved the manuscript.

\section{Funding}

The authors received no financial support for the research, authorship, and/ or publication of this article.

\section{Availability of data and materials}

The datasets generated and analysed during the current study are not publicly available due to the protection of health data regulation set by the French National Commission on Informatics and Liberty (Commission Nationale de l'Informatique et des Libertés, CNIL). Data can be available from the corresponding author after permission obtained from Santé publique France.

\section{Declarations}

Ethics approval and consent to participate

No administrative permissions were required to access the raw data mentioned in the method section. The database was constructed by Santé publique France in accordance with the French law on public health. No directly nominative data were entered in this database thus no consent to participate was required.

Consent for publication

Not applicable.

\section{Competing interests}

The authors declare that they have no competing interests.

Received: 11 March 2021 Accepted: 24 September 2021

Published online: 11 October 2021

\section{References}

1. Chen N, Zhou M, Dong X, Qu J, Gong F, Han Y, Qiu Y, Wang J, Liu Y, Wei Y, Xia J', Yu T, Zhang $X$, Zhang L Epidemiological and clinical characteristics of 99 cases of 2019 novel coronavirus pneumonia in Wuhan, China: a 
descriptive study. Lancet 2020;395(10223):507-513. https://doi.org/10.1016/ S0140-6736(20)30211-7.

2. Cauchemez S, Kiem CT, Paireau J, Rolland P, Fontanet A. Lockdown impact on COVID-19 epidemics in regions across metropolitan France. Lancet. 2020; 396(10257):1068-9. https://doi.org/10.1016/S0140-6736(20)32034-1.

3. Flaxman S, Mishra S, Gandy A, Unwin HJT, Mellan TA, Coupland H, et al. Estimating the effects of non-pharmaceutical interventions on COVID-19 in Europe. Nature. 2020;584(7820):257-61. https://doi.org/10.1038/s41586-02 0-2405-7.

4. Dehning J, Zierenberg J, Spitzner FP, Wibral M, Neto JP, Wilczek M, et al. Inferring change points in the spread of COVID-19 reveals the effectiveness of interventions. Science. 2020;369(6500).

5. Spaccaferri G, Larrieu S, Pouey J, Calba C, Benet T, Sommen C, et al. Early assessment of the impact of mitigation measures to control COVID-19 in 22 French metropolitan areas, October to November 2020. Eurosurveillance. 2020;25(50):2001974. https://doi.org/10.2807/1560-7917.ES.2020.25.50.2001 974.

6. Santé publique France. Guide pour l'identification et l'investigation de situations de cas groupés de COVID-19. Saint-Maurice: Santé publique France [cited $2020 \mathrm{dec}$ 17]. Available from: www.santepubliquefrance.fr

7. Santé publique France. COVID-19: Point épidémiologique hebdomadaire du 03 décembre 2020. Saint-Maurice: Santé publique France; 2020 Dec 3 [cited 2020 dec 17]. Available from: https://www.santepubliquefrance.fr/ma ladies-et-traumatismes/maladies-et-infections-respiratoires/infection-acoronavirus/documents/bulletin-national/covid-19-point-epidemiologiquedu-3-decembre-2020

8. Liu T, Gong D, Xiao J, Hu J, He G, Rong Z, et al. Cluster infections play important roles in the rapid evolution of COVID-19 transmission: a systematic review. Int J Infect Dis. 2020;99:374-80. https://doi.org/10.1016/j. ijid.2020.07.073.

9. Danis K, Fonteneau L, Georges S, Daniau C, Bernard-Stoecklin S, Domegan L, et al. High impact of COVID-19 in long-term care facilities, suggestion for monitoring in the EU/EEA, may 2020. Eurosurveillance. 2020;25(22):2000956. https://doi.org/10.2807/1560-7917.ES.2020.25.22.2000956.

10. Waltenburg MA, Victoroff T, Rose CE, Butterfield M, Jervis RH, Fedak KM, et al. Update: COVID-19 among workers in meat and poultry processing facilities—United States, April-May 2020. Morb Mortal Wkly Rep. 2020; 68(29).

11. Wilson E, Donovan CV, Campbell M, Chai T, Pittman K, Seña AC, et al. Multiple COVID-19 clusters on a university campus-North Carolina, august 2020. Morb Mortal Wkly Rep. 2020;69(39):1416-8. https://doi.org/10.15585/ mmwr.mm6939e3.

12. Frieden $T R$, Lee $C T$. Identifying and interrupting superspreading events-implications for control of severe acute respiratory syndrome coronavirus 2. Emerg Infect Dis. 2020;26(6):1059-66. https://doi.org/10.3201/ eid2606.200495.

13. Petersen $E$, Wasserman $\mathrm{S}$, Lee $\mathrm{S}-\mathrm{S}$, Unyeong $\mathrm{G}$, Holmes AH, Al Abri S, et al. COVID-19-we urgently need to start developing an exit strategy. Int I Infect Dis. 2020;96:233-9. https://doi.org/10.1016/j.ijid.2020.04.035.

\section{Publisher's Note}

Springer Nature remains neutral with regard to jurisdictional claims in published maps and institutional affiliations.

Ready to submit your research? Choose BMC and benefit from:

- fast, convenient online submission

- thorough peer review by experienced researchers in your field

- rapid publication on acceptance

- support for research data, including large and complex data types

- gold Open Access which fosters wider collaboration and increased citations

- maximum visibility for your research: over $100 \mathrm{M}$ website views per year

At $\mathrm{BMC}$, research is always in progress.

Learn more biomedcentral.com/submissions 